\title{
Examining the Effects of Cause-Proximity and Gender on Consumers' Response to Cause-Related Marketing: Evidence from Malaysia
}

\author{
Marhana Mohamed Anuar (Corresponding author) \\ Faculty of Management and Economics, Universiti Malaysia Terengganu \\ 21030, K.Terengganu, Malaysia \\ Tel: 60-9-668-3290 E-mail: marhana@umt.edu.my \\ Osman Mohamad \\ Graduate School of Business, Universiti Sains Malaysia \\ 11800, Penang, Malaysia \\ Tel: 60-1-3423-6298Ｅ-mail: osman@usm.my
}

Received: December 17, 2009 Accepted: March 26, 2011 doi:10.5539/ijms.v3n3p174

\begin{abstract}
Over the last decade, cause-related marketing (CRM) has become a popular marketing strategy for companies. Academic research suggests outcomes of CRM campaigns are generally positive for companies as well as for causes. For companies, CRM has been noted to increase sales and enhance companies' image. As for causes, they received greater funding and publicity. Cause-proximity which is one of the important elements of CRM's structure has been suggested to significantly influence consumers' response towards CRM. However, the impacts of cause-proximity on consumers' response are inconsistent. In this light, this paper investigates (1) the effect of cause-proximity on consumers' response to CRM. (2) the moderating role of gender on the relationship between cause-proximity and consumers' response to CRM. The results indicate that the effect of cause-proximity is insignificant while gender does influence consumers' response to CRM. Based on these results, implications for CRM campaign managers and research limitations are highlighted.
\end{abstract}

Keywords: Cause-related marketing, Cause-proximity, Gender, Consumers’ response, Malaysia

\section{Introduction}

The number of businesses that support causes has grown substantially. Corporate social responsibility (CSR) initiatives have become increasingly popular among companies in many parts of the world. Cause-related marketing (CRM) is a common and popular form of CSR; CRM links a purchase of products or services to donation to cause. According to Varadarajan and Menon (1988), CRM is a program designed to create a partnership between a company and a cause in order to raise money through product sales. Since CRM's inception 25 years ago, CRM is now flourished. The budget spent on cause-partnership was expected to reach USD1.55 billion in 2009 (IEG, 2011). The growth of CRM has been an international phenomenon (Wymer and Samu, 2009). North America and European countries have shown the most rapid growth of CRM. However, CRM has also been noted to emerge and gaining popularity in countries outside North America and Europe such as China, Malaysia, Thailand and many more.

As CRM becomes more widespread, companies must be critical in designing their CRM campaigns. This is very important as to ensure the success of CRM campaigns. CRM structural elements refer to messages that explain the CRM campaign presented to the consumer (Grau and Folse, 2007). Several CRM's structural elements such as product type (Subrahmanyan, 2003; Strahilevitz and Myers, 1998), cause-type (Cui et al. 2003; Ellen at al. 2002), cause-proximity (Grau and Folse, 2007; Ross et al. 1991) and fit between sponsoring company and the cause supported (Hou, Du and Li, 2008) have been postulated in the literature to influence consumers' response to CRM. Their findings suggest that these structural elements do influence consumers' response to the CRM campaigns. Of these elements, the effect of cause-proximity on consumer response warrants further exploration as studies that examined the effect of CRM supporting an international cause on consumer response still rather limited. Controversy exists regarding supports of local, national or international cause. Although, the survey conducted by 
Cone Roper (2000) shows that consumers prefer local as compared to national and global cause. Previous studies found the contrary (Cui et al., 2003; Ross et al., 1992). Additionally, in reality, regardless of the cause-proximity, companies support causes at various levels; local, national, regional as well as international.

The present study aims at: (1) understanding the effect of cause-proximity (local and international CRM campaigns) on consumers' attitude towards CRM and (2) examining the moderating role of gender on the relationship between cause-proximity and consumers' attitude towards CRM.

The current study contributes to this stream of research in that this study investigates the impact of cause-proximity (local and international CRM campaigns) on consumers' response to CRM and the moderating role of gender on the relationship between cause-proximity and consumers' response to CRM. Most of the past studies (Cui et al., 2003; Ross et al., 1992; Ross et al., (1990-1991); Smith and Alcorn, 1991) that study the impact of cause-proximity on consumers' response have only focus on local and national levels. Academic coverage on the impact of a company supports of international causes on consumers' response to CRM is rather scarce. Additionally, extensive review of relevant literature suggests that study that examines the effect of moderating variable on the relationship between cause-proximity and consumers' response remains marginal. Past study (Ross et al., 1992) suggests that female as compared to male shows more favorable response towards CRM. However, to the best of our knowledge, it is not clear how gender influences the impact of cause-proximity on consumers' response to CRM. Hence, examining the moderating effect of gender is important as to understand how gender influences the relationship between cause-proximity and consumers' response towards CRM.

\section{Literature Review}

CRM is growing and its growth is due to several factors such as favorable consumers' response to CRM (Cone, 2007; Brink et al., 2006; Gupta and Pirsch, 2006; Lafferty and Goldsmith, 2005; Ross et al., 1992), growing companies concern to support causes (Brink et al., 2006) as well as to increase companies' profits (Varadarajan and Menon, 1988). CRM links companies with causes. In all CRM campaigns companies need to be linked with causes. A plethora of causes exist at several levels, Varadarajan and Menon (1988) suggested that causes can be categorized into three levels, national, regional and local. However, today there are also companies that support causes at international level. CRM campaigns often mentioned or communicate to the consumer specific donations distributed to cause. It represents one specific cue that can influence consumer response to a particular CRM campaigns.

\subsection{Cause-proximity effects on consumers' response to CRM}

Varadarajan and Menon (1988) suggested that cause-proximity refers to the distance between the donation activity and the potential consumers that would make the donation. Prosocial behavior literature provides a good theoretical explanation about consumers' involvement in helping behavior and donation decision-making behavior. Prosocial behavior refers to acts that are perceived as voluntary without any expectation of external rewards and having positive social consequences. Physical distance is an important variable studied in prosocial behavior, it has been suggested that the physical distance has strong impact on the helping behavior of consumers; the physically closer the recipient of donation to the potential donor, the more likely it is that the potential donor will engage in some form of helping behavior (Bar Tal, 1976). In the context of CRM, the same logic can also be applied; CRM campaign that supports a local cause is more likely to be evaluated more favorably by the consumers than CRM that supports an international cause.

Signaling theory (Spence, 1974) suggested that cues provide employers with tangible information that are often necessary to evaluate unobservable factor. Where an employer has to make hiring decisions under an uncertain situation, an employer normally looks at certain attribute of an applicant such as level of education to assess the applicant's capabilities. Similarly, consumers in the marketplace use certain cues in order to make an evaluation about a particular product. Several factors such as price, warranties and advertising expenditures have been used by consumers as signals or cues that assist them in evaluating a company's product and help them in their decision making. In the context of CRM, CRM's structural elements act as cues that consumers can use in their evaluation and judgment about a particular CRM campaign. Consumers use the support of for example local or national cause in order to evaluate a particular CRM campaign. A CRM campaign that support a local cause might signal greater or better offer for the consumers compared to support of national and international cause.

As highlighted earlier, one recommendation in formulating CRM strategy is for companies to develop partnership with local cause. Cause-proximity represents one of the important elements of CRM's structure that has been proven to significantly influence consumers' response to CRM (Grau and Folse, 2007; Landreth, 2002). Past study (Grau and Folse, 2007) focused on how cause-proximity influences the less-involved consumers' response towards CRM. They found that the impact of cause-proximity is significant; company supports of local rather than 
national cause generates more favorable attitudes among the consumers. Likewise, older studies on cause-proximity impact on consumers' response to CRM (Smith and Alcorn, 1991; Ross et al., (1990-1991)) found similar results. In addition, Cone Roper (2000) survey found out that 55\% of consumers surveyed indicated that local causes as most important, followed by national causes $(30 \%)$ and global causes $(10 \%)$. While these papers highlight the importance of cause-proximity on generating consumers' favorable response towards CRM, the impacts of cause-proximity on consumers' response are mixed. Past studies (Cui et al., 2003; Ross et al., 1992) found out that the impact of cause-proximity is not significant. The non significant results in their studies may be due to factors such as the type of cause used in their researches. In Cui et al., (2003), the use of disasters cause for national cause and an on-going cause for local cause is one important reason of why the result is not significant. The support of disaster cause compared to an on-going cause may generate greater concern among the consumers. This is because the immediacy of supporting disaster cause plays greater role in influencing consumers' to support the national cause instead of local on-going cause in Cui et al., (2003) study. In Ross et al., (1992), although they found that the impact of cause-proximity is not significant, the results of their study show that the support of local cause is slightly more favorable than the national condition. In the real world, many companies also support causes at national and international levels. For instance, in Malaysia Motorola and Celcom supports Global Fund in their CRM campaign; throughout this campaign for each unit of Moto (Product) Red handset sold, a portion is directly contributed to the Global Fund in order to support HIV/AIDS patients in Africa (New Straits Times, February 2007).

Based on the prosocial behavior literature, it is proposed that the cause-proximity cue communicated in a CRM campaign will influence consumers' response to CRM. Consumers will response more positively towards CRM campaign that supports a local cause as it will have more direct impact on the consumers compared to CRM that supports an international cause. Hence, the following hypothesis is proposed.

H1: The attitude towards CRM will be more positive when the company supports local rather than international cause.

\subsection{The moderating role of gender}

The influence of gender on consumer response to CRM has been discussed in the past literature (e.g. Moosmayer \& Fuljahn, 2010; Ross et al., 1992; Barnes, 1991). The basis for expecting that gender will positively affect consumers' evaluation of CRM comes from the prosocial behavior literature. Research suggests that consumer characteristics such as gender (Ross et al., 1992, Barnes, 1991) influences consumers' response to CRM. The difference in response toward CRM is not biologically rooted but is attributed to the gender roles. The research on gender and prosocial behavior suggests that the help that one individual is willing to provide to other people is related to perceived sex roles (Bar-Tal, 1976). Past studies on sex roles suggest that females are more favorable toward self and other oriented appeals compared to males' (Meyers and Levy, 1988). Hence, with regards to CRM, female as compared to male is expected to give more favorable response towards CRM regardless of the cause-proximity. This is because with regards to prosocial behavior female is likely to respond to CRM campaigns more positively than male. It is therefore expected that gender may moderates the impact of cause-proximity on consumers' response to CRM. Based on the theories mentioned and review of relevant literature the following hypothesis is therefore suggested:

H2: Female as compared to male will have more positive attitude towards CRM regardless of the cause-proximity.

\section{Methodology}

The effect of cause-proximity on consumers' response and the moderating role of gender were examined in the current study. Hypotheses were tested using a 1 X 2 (cause-proximity: local and international cause) between subject design. Respondents were randomly assigned to two levels of cause proximity manipulation. The cause-proximity factor was manipulated using two set of questionnaires; Set A (local scenario) and Set B (international scenario). The advertisement featured Store X's CRM campaign with the text described the store would make a donation to (local or international) poverty funds every time consumers purchase a product from the store. The ads are invariant except for the statement stating either local or international cause. In the local condition, the ad shows a CRM campaign that supports Malaysian Against Poverty Funds (MaPF) whereas in the international condition, the ad shows CRM campaign that supports International Against Poverty Funds (IaPF) (refer Appendix).

\subsection{Sample characteristics and data collection}

The sample of the study consisted of students at the Universiti Malaysia Terengganu (UMT). The survey was conducted on several classes at UMT. Students were chosen for this study as they represent emerging potential 
market for CRM products with powerful aggregate spending. They represent a huge potential market for CRM. Moreover so, they are young enough to start establishing values and buying principles that may last a lifetime (Cui et al. 2003). A total of 120 questionnaires were distributed to students with sixty questionnaires for each condition. Out of the 120 questionnaires distributed 110 were used for data analyses. Ten questionnaires were excluded for data analyses due to incomplete and wrong answer for the manipulation check question.

\subsection{Research design and overview}

In the survey, respondents were asked to: (1) read the brief introduction describing a general CRM alliance formed between a grocery store and a cause, (2) read a CRM advertisement/scenario showing either local or international cause (refer Appendix), (3) indicate their attitude and evaluation of the CRM campaign, and (4) demographic data. To assess attitudes towards CRM, participants answered a three-item, seven-point scale questions (e.g., positive/negative, favorable/unfavorable). Cronbach's Alpha for attitudes scale is 0.87. CRM's evaluation was measured using a five-item, seven-point scale questions (e.g., like/dislike, favorable/unfavorable, wise/foolish). Coefficient alpha for this scale is 0.88 . The local condition consists of $57(51.8 \%)$ respondents and the international condition consists of 53 (48.2\%). Participants consist of $77(70 \%)$ female and $33(30 \%)$ male. The majority of the respondents are Malay $97(88.2 \%)$, followed by Chinese $5(4.5 \%)$ and others $8(7.2 \%)$. Most of the respondents are from non-business major 85 (77.3\%) and business major $25(22.7 \%)$. The demographic profile of the respondents in this study does reflect the overall students' population of UMT. Hence, is appropriate for this study.

\subsection{Data analysis}

The data analyses started with first analyzing the impact of cause-proximity on consumers' attitude towards CRM. The impact of cause-proximity on consumers' attitude towards CRM is analyzed using T-test. Next, the moderating effect of gender on the relationship between cause-proximity and consumers' attitude towards CRM is examined. It was predicted that gender would be an important determinant beyond cause-proximity for explaining consumers' response towards CRM. To explore this prediction, T-test was conducted on the influence of gender on consumers' attitude towards CRM.

\section{Findings and Discussion}

\subsection{Manipulation check}

A manipulation check for cause-proximity was assessed using a single-item measure. The respondents were questioned whether the ad featured in the questionnaire supports either a local or an international cause. All respondents correctly identified the cause featured in the ad that they were assigned to and those who failed in the manipulation check were excluded from data analyses.

\subsection{Hypotheses tests}

The current study predicted that attitudes toward CRM would differ between respondents that are exposed to local and international cause (H1). To test hypothesis $\mathrm{H} 1$, an independent-samples T-test analysis is used. Table 1 shows the result of the influence of cause-proximity on consumers' attitude towards CRM. This hypothesis is not supported. The results on Table 1 show that the influence of cause-proximity towards consumers' attitude towards CRM is not significant. First, the results provide empirical evidence that cause-proximity effect is not so influential in generating more favorable responses towards CRM among consumers. The finding of the current study is similar with past studies (Cui et al., 2003; Ross et al., 1992) that found out the impact of cause-proximity on consumers' response to CRM is insignificant. The finding of the current study differs from the results of previous studies (Grau and Folse, 2007; Smith and Alcorn, 1991; Ross et al., (1990-1991)) that found out that the effect of cause-proximity is significant.

In general, majority of the respondents have favorable attitude towards CRM. This is evidence as the overall mean for attitude towards CRM is 5.39. Although the effect of cause-proximity is not significant, the mean for attitude towards CRM is slightly higher in the local as compared to the international condition. In addition, the mean for local condition $($ mean $=5.47)$ is higher than both the overall mean $($ mean $=5.39)$ and the international condition mean (mean $=5.30$ ). The results are partially consistent with the prosocial behavior literature that predicts there is a positive relationship between proximity and donation behavior. Similarly, signaling theory predicts that cues provide tangible information for consumers to evaluate an unobservable factor. The finding of this study suggests that the cause-proximity cue (supporting local or international cause) may have not provides enough tangible information for the consumers to evaluate the CRM campaign. In this context, CRM campaign that supports local cause may not signal a greater or better offer for the consumers. In sum, it can be concluded that regardless of the cause-proximity; consumers are willing to support causes at both levels. 


\subsection{Moderating effect}

$\mathrm{H} 2$ examined the moderating influence of gender on the relationship between cause-proximity and consumers' attitude toward CRM. H2 states that the influence of cause-proximity is more positive on male as compared to female. In order to explore the moderating role of gender on the relationship between cause-proximity and consumers' attitude toward CRM, an independent sample t-test is performed. The independent sample t-test is used to assess the difference in attitude towards CRM in case of female and male irrespective of the cause-proximity conditions. Table 2 shows the influence of gender on consumers' response variable. In addition, Figure 1 shows the moderating effects of gender on the relationship between cause-proximity and attitude towards CRM.

The results show a very interesting finding concerning the differences in response towards CRM between male and female. Overall the result shows that, male compared to female have slightly more favorable response towards CRM as depicted in Table 2. However, the results show that the impact of gender is not significant (t-value is 1.127). Additionally, the power of this moderating effect is assessed separately between the local and international conditions. The result shows that gender does not have a significant effect on the relationship between local and attitude towards CRM. However, the effect of gender on the relationship between international and attitude towards CRM shows a significant result (t-value is 1.72) but in the opposite direction. Contradict to as what was hypothesized; female instead of male is much more affected by the cause-proximity. Therefore, H2 is not supported. Male was consistent in their response towards CRM regardless of the cause-proximity. This indicates that male has not been very much influenced by the cause-proximity of the CRM campaign. On the contrary, female response towards CRM was very much influenced by the cause-proximity of the CRM campaign. Female response towards CRM was less favorable in the CRM campaign that support international cause compared to local cause. Meanwhile, male showed consistent supports toward CRM regardless of the cause-proximity.

One possible explanation of the non-significant finding could be due to the type of cause used in this study. The male respondents may feel that poverty cause is very important and thus need to be supported regardless of the proximity of the cause. Additionally, the small number of male respondents in the current study might have also influenced the results of this study. As for the female respondents, they have shown more favorable response towards local poverty cause compared to the international poverty cause. This may be due to the nurturing nature of female as suggested in the prosocial literature and thus felt more attached or closed to the local cause.

\section{Conclusions}

The present study assesses the effect of cause-proximity and gender on consumers' response to cause-related marketing. Using an experimental study on a total of 110 respondents, the current study shows that cause-proximity does not significantly influence consumers' attitude toward CRM. Second, the current study examines the effect of cause-proximity on male and female. With regards to the moderating effect of gender on the relationship between cause-proximity and attitude towards CRM, the results of this study shows that cause-proximity does not impact male respondents attitudes towards CRM very much. On the contrary cause-proximity does impact attitudes towards CRM for female respondents as such the female prefer to support local cause as compared to international cause.

The findings of this study can be used by managers in designing their CRM campaigns in the future. Overall, male have more favorable response towards CRM than female and that female response towards CRM is influenced by cause-proximity. In sum, if companies intend to increase attitudes toward CRM for CRM campaigns targeted at female consumers they should design a campaign that supports local cause. On the contrary, for CRM campaigns targeted at male consumers cause-proximity is of less concern, hence companies may design CRM campaigns that support either local or international causes. Male respondents have high attitudes towards both local and international causes.

\section{Limitations of the Study}

This study is limited in some ways, but these limitations generate interesting questions for the future research topics in this area. First, the study uses students as the respondents. Further investigation on the non-students sample would be helpful in understanding how this construct impact the consumers in general. Second, the cause selected for the current study which is poverty cause may generate favorable responses for the consumers. It would be interesting to explore whether other causes such as education and health would increase or decrease consumers' response to CRM. Third, this study only measured the moderating impact of gender, future research should continue to explore other moderating factors such as race, marital status and cause involvement. 


\section{References}

Barnes, N. G. (1992), Determinants of consumer participation in cause-related marketing campaigns, American Business Review, June, 21-24.

Bar, Tal, D. (1976). Prosocial Behavior: Theory and Research. New York: Halsted Press.

Berglind, M., \& Nakata, C. (2005). Cause-related marketing: more buck than bang? Business Horizon, 48, 443-453.

Brink, D. V. D., Odekerken-Schroder, G., \& Pauwels, P. (2006). The effect of strategic and tactical cause-related marketing on consumers' brand loyalty. Journal of Consumer Marketing, 23(1), 15-25.

Cone Roper Survey (2000). [Online] Available: http://www.coneinc.com.

Cone (2007). Cone cause evolution \& environmental survey. [Online] Available: http://www.coneinc.com/files/2007 ConeSurveyReport.pdf.

Cui, Y., Trent, E. S., Sullivan, P. M., \& Matiru, G. N. (2003). Cause-related marketing: how generation Y respons. International Journal of Retail \& Distribution Management, 31(6), 310-320.

Drumwright, M. E. (1996). Company advertising with a social dimension: The role of noneconomic criteria. Journal of Marketing, 60(October), 71-87.

Grau, S. L., \& Folse, J. A. G. (2007a). Cause-related marketing (CRM) The influence of donation proximity and message framing cues on the less-involved consumer. Journal of Advertising, 36(4), 19-33.

Grau, S. L., \& Folse, J. A. G. (2007b). Cause-related marketing (CRM): The influence of donation and message-framing cues on the less-involved consumer. Journal of Advertising, 36(4), 19-33.

Gupta, S., \& Pirsch, J. (2006). The company-cause-customer fit decision in cause-related marketing. Journal of Consumer Marketing, 23(6), 314-326.

IEG Sponsorship Report. [Online] Available: http://www.sponsorship.com (February 3, 2011).

Lafferty, B. A., \& Goldsmith, R. E. (2005). Cause-brand alliances: does the cause help the brand or does the brand help the cause? Journal of Business Research, 58(4), 423-429.

Landreth, S. (2002). For a Good Cause: the Effects of Cause Importance, Cause Proximity, Congruency and Participation Effort on Consumers' Evaluation of Cause-related Marketing. ProQuest Company Press, Ann Arbor, MI.

Moosmayer, D. C., \& Fuljahn, A. (2010). Consumer perceptions of cause-related marketing. Journal of Consumer Marketing, 27 (6), 543-549.

Myers L. V. (1988). The influence of sex roles on judgments. Journal of Consumer Research, 14(March), 522-530.

New Straits Times, February 8, 2007, p.C2.

Ross, J. K. III, Stutts, M. A., \& Patterson, L. T. (1990-1991). Tactical considerations for the effective use of causerelated marketing. Journal of Applied Business Research, 7(2), 58-65.

Ross, J. K. III, Patterson, L. T., \& Stutts, M. A. (1992). Consumer perceptions of organizations that use cause-related marketing. Journal of the Academy of Marketing Science, 20(1), 93-97.

Smith, S., \& Alcorn, D. S. (1991). Cause marketing: a new direction in the marketing of corporate social responsibility. Journal of Consumer Marketing, 8(Summer), 19-35.

Spence, M. (1974). Market Signaling. Cambridge: Harvard University Press.

Smith, C., \& Alcorn, D., (1991). Cause marketing: a new direction in the marketing of corporate social responsibility. Journal of Consumer Marketing, 8(3), 19-35.

Varadarajan, P. R., \& Menon, A. (1988). Cause-related marketing: a coalignment of marketing strategy and corporate philanthropy. Journal of Marketing, 52(3), 58-78.

Watson, T. (2006), Consumer philanthropy: nonprofits spend billions to reach consumers. Huffington Post, [Online] Available: http://www.huffingtonpost.com/tom-watson/consumer-philanthropy-no_b_36261.html.

Wymer, W., \& Samu, S. (2009). The influence of cause-marketing associations on product and cause brand value. International Journal of Nonprofit Voluntary Sector Marketing, 14, 1-20. 
Table 1. The effect of cause-proximity on consumers' attitude towards CRM

\begin{tabular}{|l|l|l|l|l|l|}
\hline $\begin{array}{l}\text { Consumers' } \\
\text { Response } \\
\text { Variable }\end{array}$ & Overall Mean & \multicolumn{2}{|l|}{ Cause-proximity } & T-value & P-value \\
\cline { 3 - 4 } & & Local & International & & \\
\hline Attitude & 5.39 & $\begin{array}{l}5.47 \\
\text { SD }(1.16)\end{array}$ & $\begin{array}{l}5.30 \\
\text { SD }(1.0)\end{array}$ & .860 & .392 \\
\hline
\end{tabular}

Table 2. Attitude towards CRM bassed on gender

\begin{tabular}{|c|c|c|c|c|c|c|c|c|}
\hline & CRM condition & $\mathrm{n}$ & Mean & STD & $\begin{array}{l}\text { Std. } \\
\text { error } \\
\text { mean }\end{array}$ & $T$ & d.f & $\begin{array}{c}\text { P } \\
\text { (one-t } \\
\text { ailed) }\end{array}$ \\
\hline $\begin{array}{c}\text { Attitude } \\
\text { towards } \\
\text { CRM }\end{array}$ & $\begin{array}{l}\text { Male } \\
\text { Female }\end{array}$ & $\begin{array}{l}33 \\
77\end{array}$ & $\begin{array}{l}5.57 \\
5.31\end{array}$ & $\begin{array}{l}1.07 \\
1.09\end{array}$ & $\begin{array}{l}.34 \\
.17\end{array}$ & 1.127 & 108 & .131 \\
\hline $\begin{array}{c}\text { Attitude } \\
\text { towards } \\
\text { CRM }\end{array}$ & $\begin{array}{l}\text { Local-male } \\
\text { Local-female }\end{array}$ & $\begin{array}{c}9 \\
48\end{array}$ & $\begin{array}{l}5.59 \\
5.45\end{array}$ & $\begin{array}{l}1.02 \\
1.19\end{array}$ & $\begin{array}{l}.43 \\
.83\end{array}$ & .332 & 55 & .370 \\
\hline $\begin{array}{c}\text { Attitude } \\
\text { towards } \\
\text { CRM }\end{array}$ & $\begin{array}{l}\text { International-male } \\
\text { International-female }\end{array}$ & $\begin{array}{l}24 \\
29\end{array}$ & $\begin{array}{l}5.56 \\
5.08\end{array}$ & $\begin{array}{l}1.10 \\
0.86\end{array}$ & $\begin{array}{l}.23 \\
.16\end{array}$ & 1.72 & 51 & $.046^{* *}$ \\
\hline
\end{tabular}

Estimated Marginal Means of attitude

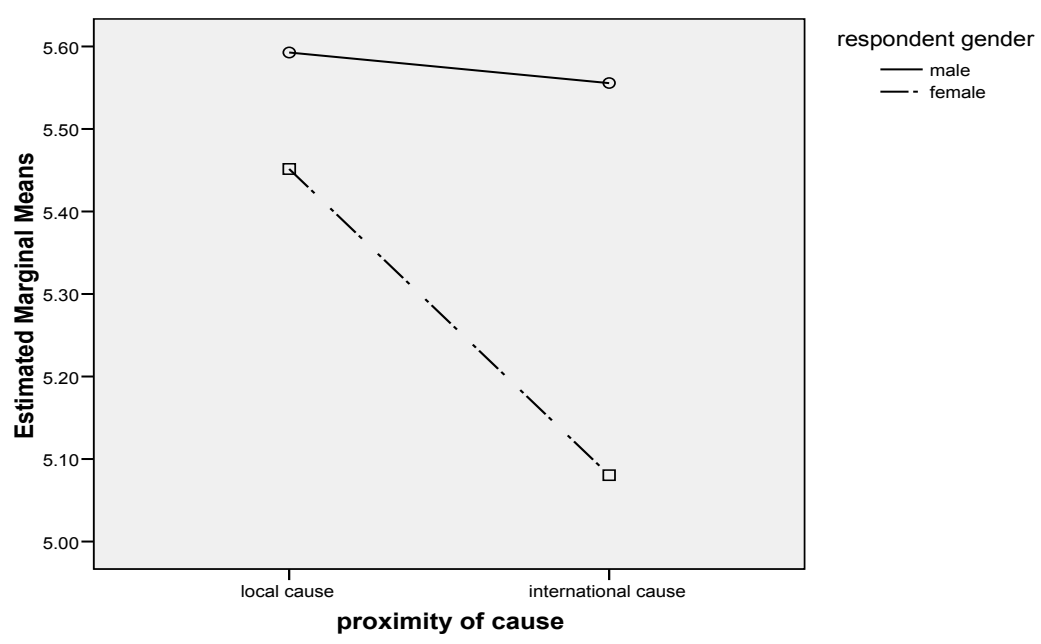

Figure 1. The moderating effect of gender on consumers' attitude towards CRM 
Appendix

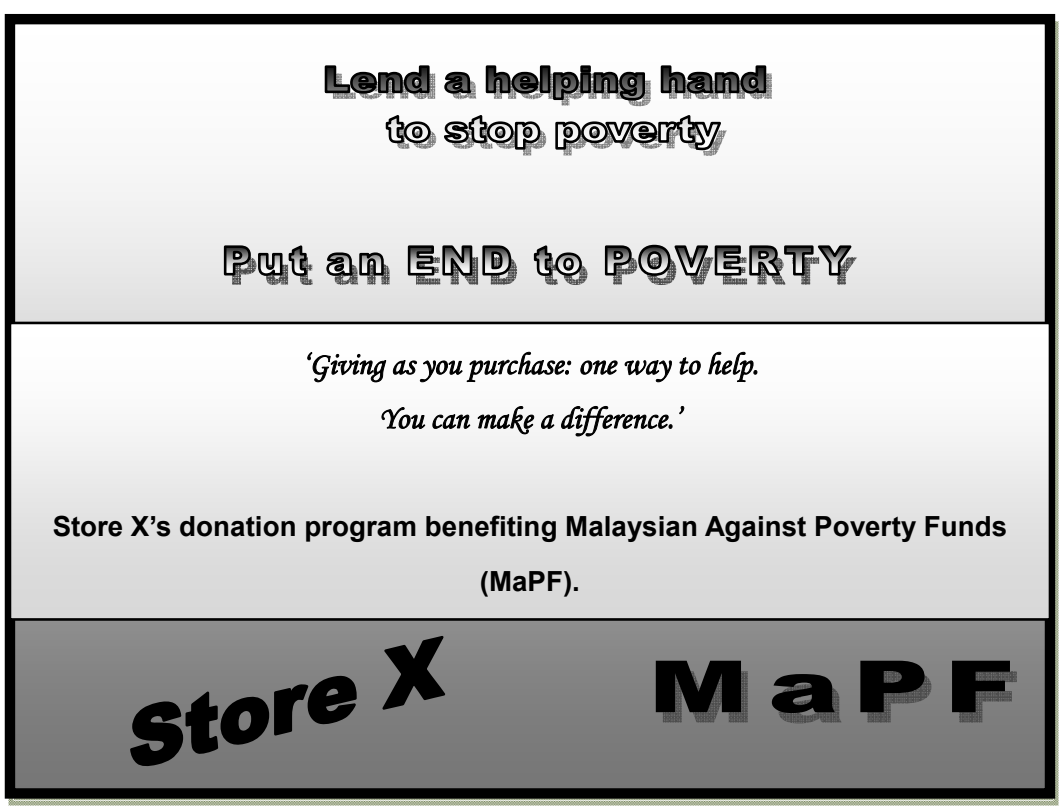

Experiment Stimuli: Local condition

\section{Lend a helping hand \\ ఛ० s\{్p [poventy}

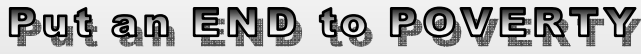

'Giving as you purchase: one way to help.

You can make a difference.'

Store X's donation program benefiting International Against Poverty Funds (laPF).

\section{store $x$ \\ $x$}

Experiment Stimuli: International condition 